\title{
Correction: Antigenic cartography of immune responses to Plasmodium falciparum erythrocyte membrane protein 1 (PfEMP1)
}

\section{The PLOS Pathogens Staff}

There are a number of errors in the caption for Fig 2, "Antisera maps for IgG and IgM" that arose during typesetting. Please see the complete, correct Fig 2 caption here. The publisher apologizes for the errors.

\section{G open Access}

Citation: The PLOS Pathogens Staff (2019)

Correction: Antigenic cartography of immune responses to Plasmodium falciparum erythrocyte membrane protein 1 (PfEMP1). PLoS Pathog 15 (8): e1008018. https://doi.org/10.1371/journal. ppat.1008018

Published: August 15, 2019

Copyright: @ 2019 The PLOS Pathogens Staff. This is an open access article distributed under the terms of the Creative Commons Attribution License, which permits unrestricted use, distribution, and reproduction in any medium, provided the original author and source are credited. 

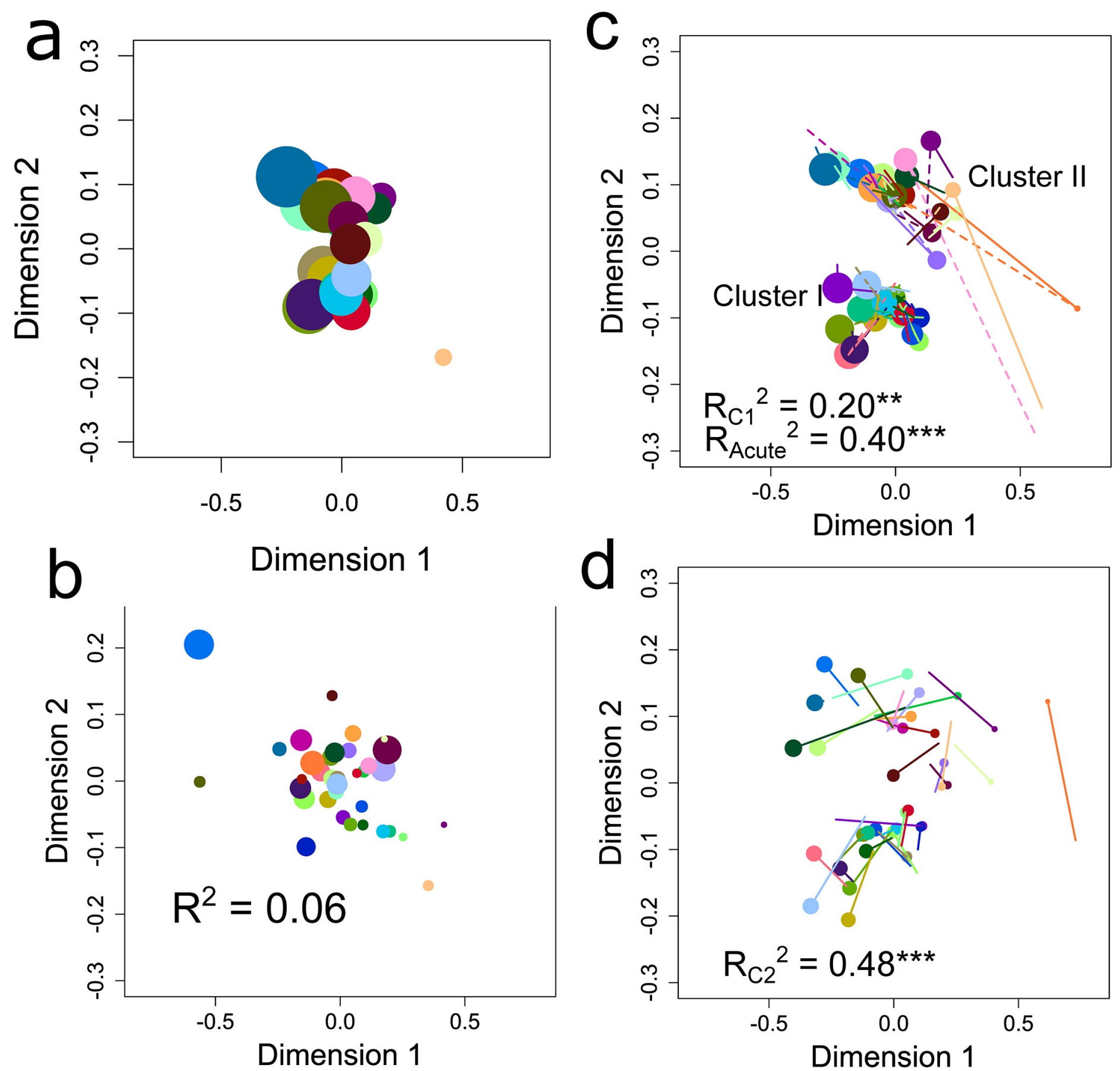

Fig 2. Antisera maps for IgG and IgM. Maps were constructed from data on a, IgG at the acute timepoint; b, IgM at the acute timepoint; $\mathbf{c}$, IgG at timepoint C2 (the consensus antisera map); d, IgM at timepoint C2. In c, solid and dashed lines point to positions in the map for IgG at the acute (as in a) and C1 timepoints, respectively. In $\mathbf{d}$, solid lines point to positions in the consensus antisera map shown by the points in c. Symbol size is proportional to the antisera's average $\log _{10} \mathrm{OD}_{\text {value at the }}$ timepoint indicated. $\mathrm{R}^{2}$ values represent goodness-of-fit to the consensus map with subscripts indicating the timepoint of the map being compared and asterisks indicating significance $\left({ }^{* * *}, \mathrm{P}<0.001{ }^{* *}, \mathrm{P}<0.01\right)$.

https://doi.org/10.1371/journal.ppat.1008018.g001

\section{Reference}

1. Tuju J, Mackinnon MJ, Abdi AI, Karanja H, Musyoki JN, Warimwe GM, et al. (2019) Antigenic cartography of immune responses to Plasmodium falciparum erythrocyte membrane protein 1 (PfEMP1). PLoS Pathog 15(7): e1007870. https://doi.org/10.1371/journal.ppat.1007870 PMID: 31260501 